\title{
De espionagem à produção do conhecimento comum e heterogêneo na escola: a participação das crianças na pesquisa em educação
}

\author{
From espionage to the production of common and heterogeneous \\ knowledge at school: children's participation in educational research
}

Fernanda Maria Santos Albuquerque Mestre em Educação Contemporânea pela Universidade Federal de Pernambuco Docente da rede municipal de ensino de Toritama - PE, Brasil. fernanda.m.s.albuquerque@gmail.com

\begin{abstract}
Conceição Gislâne Nóbrega Lima de Salles
Doutora em Educação pela Universidade Federal de Pernambuco Professora Associada II do Centro Acadêmico do Agreste da Universidade Federal de Pernambuco, onde atua no curso de graduação em Pedagogia e no Programa de Pós-graduação em Educação Contemporânea

(PPGEduc), como docente permanente. É coordenadora do PPGEduc. cgislane@terra.com.br

Nádia Priscila de Lima Carvalho Mestre em Educação Contemporânea pela Universidade Federal de Pernambuco nadiapri1@hotmail.com
\end{abstract}

Resumo: Apresenta a educação e, em específico, a produção do conhecimento comum e heterogêneo na escola, como direito humano e social, sobretudo, das crianças. Pensa a infância não só como categoria geracional, mas também como condição da experiência e denota a recepção das crianças ao mundo e a experiência como sentidos da educação. Traz uma pesquisa com perspectiva cartográfica realizada junto a 41 (quarenta e uma) crianças e 06 (seis) professoras dos anos iniciais do Ensino Fundamental e destaca fragmentos que enfatizam a diferença entre a espionagem e a produção do conhecimento comum e heterogêneo na escola. Dessa forma, questiona a realização de pesquisas em educação sobre crianças e reflete acerca da produção de conhecimento com as crianças na escola. Aponta outros modos de pensar o acesso à educação e a luta por este direito.

Palavras-chave: Crianças. Direito à educação. Participação em pesquisa.

Abstract: It presents education and, in particular, production of common and heterogeneous knowledge at school as a human and social right, especially for children. It thinks of childhood not only as a generational category, but also as a condition of experience and denotes the reception of children in the world and an experience as meanings of education. It brings a research with a cartographic perspective conducted out together 41 (forty-one) children and 06 (six) teachers in the early years of elementary school and from fragments that emphasize the difference between the espionage and the production of common and heterogeneous knowledge at school. Thus, it questions the conduct of research in education on children and reflects on the production of knowledge with children at school. It points to the resignification of access to education and the struggle for this right.

Key-words: Children. Right to education. Research participation. 


\section{Dialogia}

ALBUQUERQUE, Fernanda Maria Santos; SALLES, Conceição Gislane Nóbrega Lima de; CARVALHO, Nádia Priscila de Lima. De espionagem à produção do conhecimento comum e heterogêneo na escola: a participação das crianças na pesquisa em educação

\section{Introdução}

A educação está no íntimo dos direitos humanos, seja porque ela mesma constitui um direito inalienável de toda pessoa, seja porque a educação corrobora a garantia dos demais direitos. Esta amálgama entre direito humano e educação soma forças à construção de uma sociedade mais justa e igualitária, ao respeito às diferenças, inclusive às diferenças entre pessoas adultas e crianças.

Destacamos que a "majoritariedade adultocêntrica" pode ferir a liberdade e a igualdade em dignidade e em direitos das pessoas presentes no artigo $1^{\circ}$ da Declaração Universal dos Direitos do Homem (ONU, 1948), proclamada pela Assembleia Geral das Nações Unidas em Paris, em 10 de dezembro de 1948. Neste sentido, propomos a reflexão acerca do direito à educação, como direito humano e social, com ênfase na liberdade de pessoas adultas e de crianças, bem como na igualdade entre estas, de pensar e atuar em sua própria escola.

Não ignoramos a luta pela escolarização de toda criança e os esforços ainda necessários à defesa da escola pública, obrigatória, gratuita e de qualidade. No entanto, o direito à educação não pode ser confundido ou restrito à escolarização, conforme denota Brandão (2014). É preciso alçar a cidadania escolar para toda criança, o que implica em "padrões de escolaridade que permitem de fato se fazer presente em condições de igualdade no espaço público” (BRANDÃO, 2014, p. 1).

O direito à cidadania escolar e a equidade cidadã, apontados por Brandão (2014), levamnos além da presença física das crianças nas instituições de ensino, colocam-nos frente ao direito das crianças à participação na produção de conhecimento sobre o mundo, a educação, a escola e sobre as outras pessoas e sobre si mesmas.

As crianças têm direito a pensar e atuar em seus currículos, em seus processos de ensino e aprendizagem, em suas experiências na escola e uma das formas para tanto é a realização de pesquisas na área de educação com a participação das mesmas. Fazer pesquisa em educação é, conforme Brandão (2012), pensar a educação e o desenho das políticas que a configura.

Dessa forma, nos próximos pontos, refletimos sobre a relação entre infância e educação, destacando os sentidos da infância denotados à educação; trazemos uma pesquisa em educação e com crianças e destacamos fragmentos que enfatizam a participação das mesmas em pesquisas realizados na escola, diferenciando a espionagem de uma produção do conhecimento comum e heterogêneo; e, com isso, apontamos outros modos de pensar o acesso à educação e a luta por este direito. 


\section{Dialogia}

ALBUQUERQUE, Fernanda Maria Santos; SALLES, Conceição Gislane Nóbrega Lima de; CARVALHO, Nádia Priscila de Lima. De espionagem à produção do conhecimento comum e heterogêneo na escola: a participação das crianças na pesquisa em educação

\section{Infância e educação}

Pensar em infância implica pensar em educação. Educação e infância implicam o pensar, a produção de conhecimento, na medida em que propõem a relação com um mundo já existente e a atuação no mesmo. Ambas, educação e infância, radicalizam a existência, o nascimento e, distintamente, estão intimamente relacionadas às crianças.

A educação é atrelada ao nascimento, reforça-nos Arendt (2000). A recepção dos novos seres ao mundo (e a entrega deste último aos primeiros) denota a importância de pensar a educação, de produzir conhecimentos acerca da mesma, de (re)fazê-la continuamente. A educação, ela mesma “jamais permanece tal qual é, porém, se renova continuamente através do nascimento, da vinda de novos seres humanos" (ARENDT, 2000, p. 234).

Conforme Arendt (2000), é preciso amar o mundo e responsabilizar-se por ele através da educação. Podemos pensar a educação e, consequentemente, o mundo a partir da realização de pesquisas e fazer isso de forma compartilhada com as crianças, em um plano comum e heterogêneo que implica em dar voz às crianças na escola, ou melhor: "Não, não é dar a voz: é escutá-la ali, onde já se fazia presente" (SKLIAR, 2019, p. 84).

Presença e participação não são palavras sinônimas. A presença das crianças em pesquisas pode ser considerada tardia, sobretudo em pesquisas no campo educativo. A ausência das crianças nos processos de produção do conhecimento persistiu até o século XX, quando a história, a antropologia, a medicina, a psicologia, o direito, a sociologia e a filosofia efervesceram a necessidade de pesquisar sobre a importância histórica atribuída às mesmas, sobre seus modos de ser, modos de se desenvolver, sobre as garantias da infância e com as crianças.

Dentre essas áreas específicas do conhecimento, destacamos perspectivas da sociologia e da filosofia que buscaram outros significados para e junto à infância, enfatizando a diferença entre pesquisas sobre crianças e pesquisas com crianças. A exemplo, Pinto e Sarmento (1997), representantes da Sociologia da Infância, apontaram-nos a relevância social da infância no final do século XX, uma relevância caracterizada pelos mesmos como paradoxal, quando o mundo acorda para a existência das crianças ao mesmo tempo em que estas são em menor número relativo; quando a estas se atribui o futuro do mundo em um presente de opressão; quando para estas se promulgam leis de proteção, provisão e participação e, ao mesmo tempo, variáveis econômicas, sociais e culturais praticam a inobservância de seus direitos.

Pinto e Sarmento (1997) fortalecem o direito de participação social das crianças ao insistirem no reconhecimento da capacidade de produção simbólica por parte das mesmas e na constituição de suas representações e crenças em sistemas organizados, o que denominam de 
ALBUQUERQUE, Fernanda Maria Santos; SALLES, Conceição Gislane Nóbrega Lima de; CARVALHO, Nádia Priscila de Lima. De espionagem à produção do conhecimento comum e heterogêneo na escola: a participação das crianças na pesquisa em educação

culturas infantis. Os mesmos apontam a escuta da vOz das crianças em pesquisas e enfatizam a necessidade de partir das crianças para o estudo das realidades de infância.

Refletimos que voz e infância para os autores se dão no singular, pois, os mesmos destacam a infância como construção social dotada de certa homogeneidade, de fatores transversais à posição de classes, ao gênero, à etnia ou à cultura que caracterizam um grupo social distinto na vida em sociedade, que caracterizam, por exemplo, os maiores e os menores de idade, uma categoria geracional que, para além da determinação de etapas cronológicas, é dotada de direitos e configura sujeitos sociais.

$\mathrm{Na}$ continuação da poda da supremacia adultocêntrica sobre as crianças, uma perspectiva filosófica afirma a infância como experiência, destacando sua multiplicidade, reforçando a diferença que a perpassa. Ao problematizar a temporalidade, Kohan (2007) possibilita-nos pensar a infância que se dá em um tempo como intensidade (Aión) e não somente em um tempo como cronologia (Chrónos). Kohan (2007) faz-nos questionar homogeneidades como a maioridade. O autor tornanos cúmplices de uma infância de outros vivos, distantes, irreconhecíveis, estrangeiros.

Afora estas áreas específicas do conhecimento, a filosofia e a sociologia, Kramer (2002, p. 45-46) afirma-nos que a arte em geral também ajudou a constituir este outro modo de olhar a infância, de traçar os seus modos de olhar, pensar, sentir e imaginar o mundo. Para a autora, a arte encontra maneiras outras de falar da infância, maneira distante da natureza histórica e social atribuída à criança.

Neste sentido, essas discussões apontam para o deslocamento de perspectiva, a necessidade de distanciamento de perspectivas adultocêntricas. Contamos com o pensar infantil para acessar outra educação, ir além do dado e do previsto.

\section{A produção de conhecimento comum e heterogêneo com crianças na escola}

Em uma pesquisa realizada junto a 41 (quarenta e uma) crianças, com idades entre 7 e 9 anos, e 06 (seis) professoras dos anos iniciais do Ensino Fundamental, especificamente do $2^{\circ}$ e do $3^{\circ}$ anos, de uma escola pública da Mesorregião do Agreste do estado de Pernambuco, buscamos cartografar os (des)encontros (im)possíveis da infância, da experiência estética e da arte na escola.

Juntas, prezando pela liberdade, autonomia e pelos outros princípios éticos das pesquisas em Ciências Humanas e Sociais constantes na Resolução nº 510, de 07 de abril de 2016, traçamos um plano comum e heterogêneo de produção de dados, pois é no plano, plano coletivo de forças, que o ponto de vista de quem pesquisa e a própria pesquisa dissolvem-se (PASSOS; KASTRUP; ESCÓSSIA, 2015). 


\section{Dialogia}

ALBUQUERQUE, Fernanda Maria Santos; SALLES, Conceição Gislane Nóbrega Lima de; CARVALHO, Nádia Priscila de Lima. De espionagem à produção do conhecimento comum e heterogêneo na escola: a participação das crianças na pesquisa em educação

Ao pesquisar, entregamo-nos aos mais variados sentidos não classificáveis ou mapeáveis e contamos com a cartografia para registrar nossos movimentos. Assumimos a cartografia como a produção de mapas moventes povoados por nômades e composto a partir de matérias de expressão e linguagens que favorecem a passagem das intensidades (ROLNIK, 2014).

Nesta direção, atamos laços, partilhamos os mais variados "espaçostempos" escolares; dispomo-nos aos imprevistos, aos (des)encontros (im)possíveis e às conversas. Envolvemo-nos com o mistério e a magia das práticas da conversa de que falam Ferraço e Alves (2018). Destacamos que, segundo estes autores,

quando nos envolvemos em conversas tecidas por relações de afeto-amizades, quando nos predispomos a entrar em uma rede de conversações em nossas pesquisas, buscando potencializar encontros com os praticantes dos cotidianos das escolas, nunca saberemos aonde as conversas poderão nos levar e, para nós, aí reside o mistério e a magia das práticas da conversa: nos deixar levar pelas redes e pelas diferenças que atestam a permanente novidade da vida (2018, p. 6263).

Assim, conversando em pequenos grupos, escolhemos nomes fictícios para as pessoas participantes da pesquisa...
-Raiz?
-Hobin Wood gamer, ele... é um arqueiro.
-Eu vou ser Oôoôoooôo... eu vou ser Taržan.
-Gato-aranha, eu vou botar.
-Lobo? Lobo-guará? ...Lobo-guará, eu sou o Lobo-guará... senão, de Sauro. Eu posso nascer planta.
-E a senhora é o que tia? Perguntou o Tarzan. Decidi.
-Não sei... flor... Pensava uma das professoras
-Rosas que é óbvio. É muito óbvio Rosa.
-Pronto, Rosa e Margarida
-Eu gosto da rosa (...) en gosto da amarela.
-Eu Jasmim.

-Qual é o nome daquele Pokémon que ele é feito das plantas? ...Bulbassauro ...Eu posso me transformar em humano e em Bulbassauro ...Ob tia, a senhora pode me chamar de Bulbo ou,

-Brisa. Brisa é aquele vento bem fininho que bate na gente, que é bem gostoso, bem fininho...

Nasceram animais e fenômenos da natureza, brotaram flores, simbioses múltiplas e simultâneas, a partir das quais acessamos outros sentidos (sobretudo sentidos infantis) dados à arte, à infância e à experiência estética na escola. Juntas, quisemos, inicialmente, criar e expor mapas dos tesouros que indicavam encontros possíveis com a arte, a infância e a experiência estética na escola, mas o Lobo Alfa deu-nos uma ideia melhor: uma instalação... 


\section{Dialogia}

ALBUQUERQUE, Fernanda Maria Santos; SALLES, Conceição Gislane Nóbrega Lima de; CARVALHO, Nádia Priscila de Lima. De espionagem à produção do conhecimento comum e heterogêneo na escola: a participação das crianças na pesquisa em educação

- (...) tipo, como se fosse um jogo, a pessoa esconde, esconde um monte de coisa na escola e depois a gente cria mesmo na vida real?! Pras outras turmas tentar achar! E quem achar (...) A gente faz. isso no intervalo, que dá tempo! Tem 15 minutos. Propôs de defendeu o Lobo Alfa.

Combinamos. Deu tempo. Fizemos.

Figura 01 - A instalação

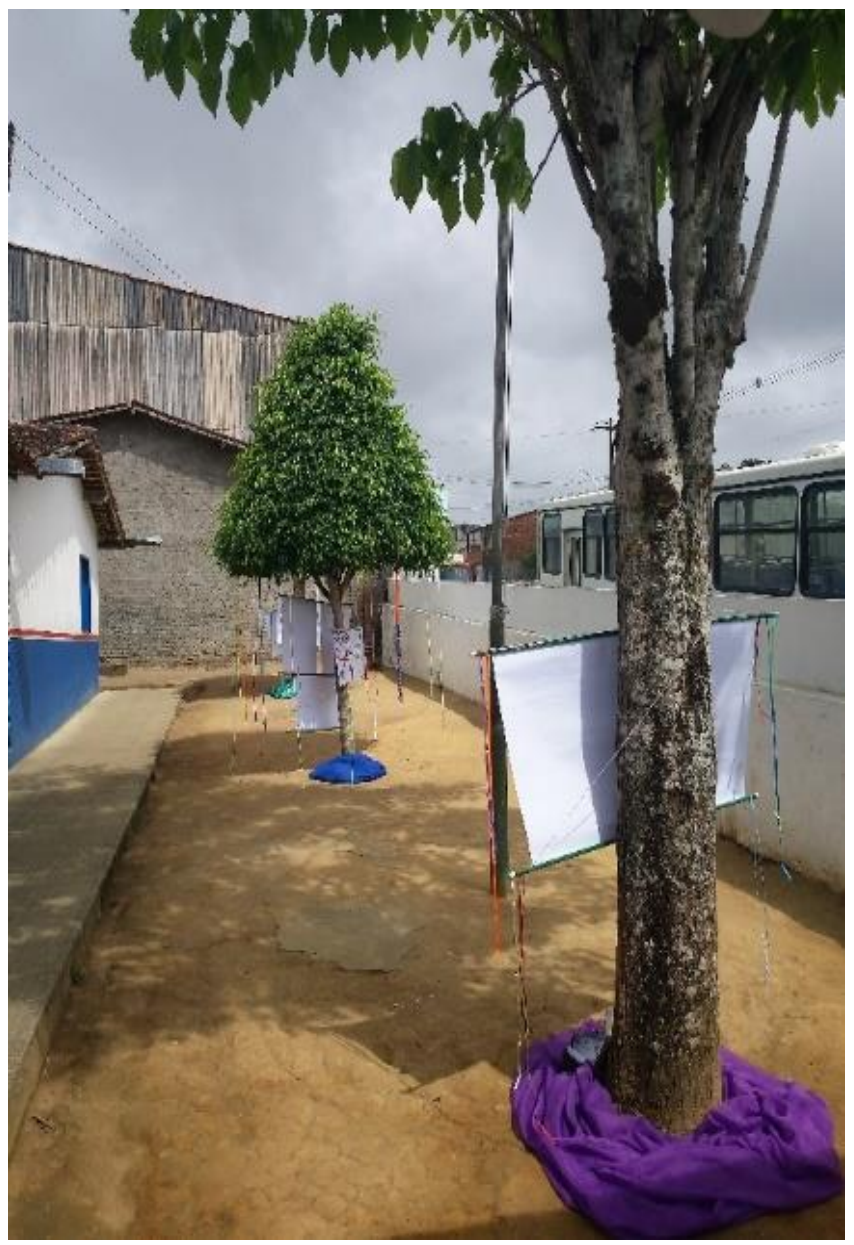

Fonte: as autoras (2018). 


\section{Dialogia}

ALbUQUERQUE, Fernanda Maria Santos; SALLES, Conceição Gislane Nóbrega Lima de; CARVALHO, Nádia Priscila de Lima. De espionagem à produção do conhecimento comum e heterogêneo na escola: a participação das crianças na pesquisa em educação

Figura 02 - Os mapas dos tesouros

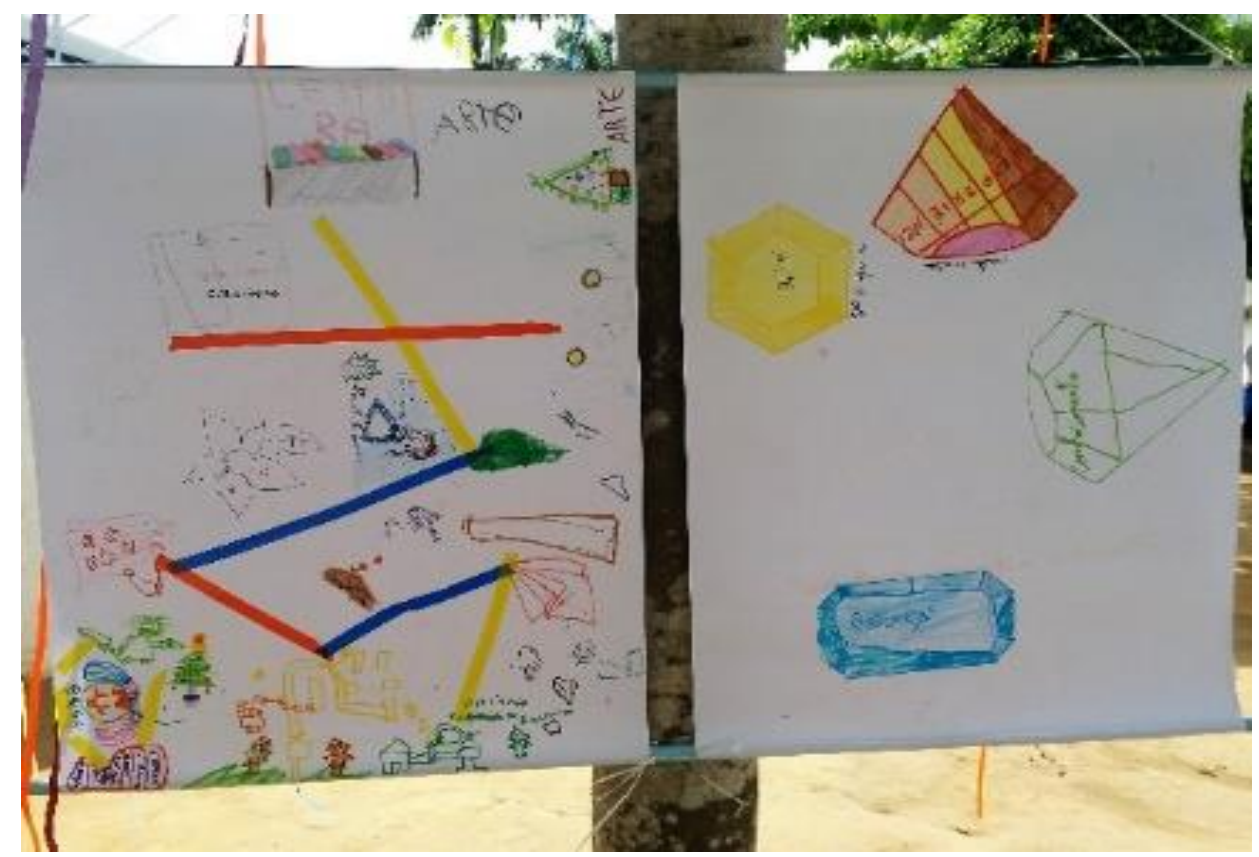

Fonte: as autoras (2018).

Figura 03 - Os mapas dos tesouros

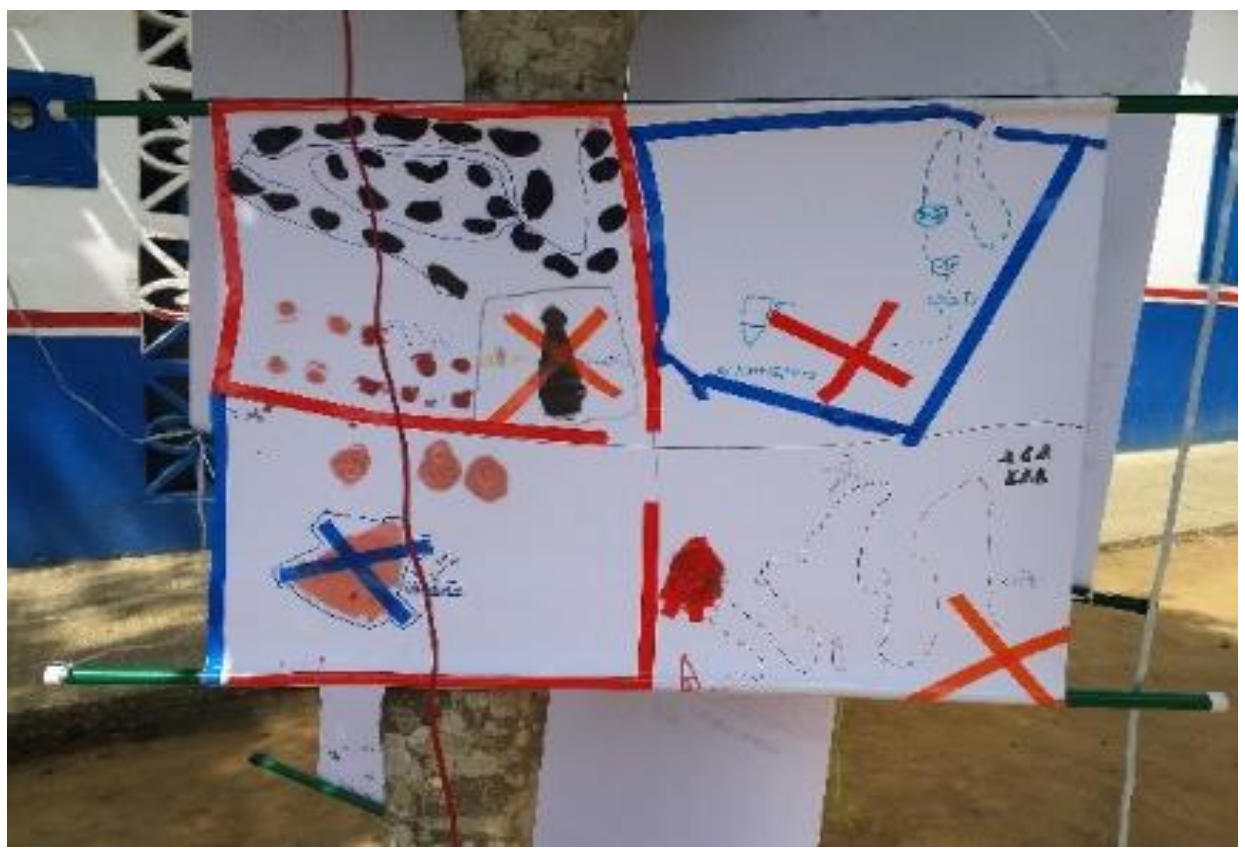

Fonte: as autoras (2018).

Ao longo do caminho consideramos que os (des)encontros (im)possíveis desfalecem todo saber e poder totalitários na escola. A infância parece brotar entre os anos iniciais do Ensino Fundamental, mesmo quando estes parecem "espaçostempos" impróprios à mesma, quando condizem muito mais com a maioridade e suas predeterminações. A infância faz-se "condição da 


\section{Dialogia}

ALBUQUERQUE, Fernanda Maria Santos; SALLES, Conceição Gislane Nóbrega Lima de; CARVALHO, Nádia Priscila de Lima. De espionagem à produção do conhecimento comum e heterogêneo na escola: a participação das crianças na pesquisa em educação

experiência" (KOHAN, 2007). Mesmo em meio à resistência ao caráter inefável na educação escolar, a experiência estética anima a escola, faz a mesma pulsar. Assim, a experiência estética envolve sobretudo a arte e seu ensino na escola, mesmo com (e, talvez, em virtude de) todo desfavor institucionalizado relacionado a esta área específica do conhecimento.

Os (des)encontros (im)possíveis da infância, da experiência estética e da arte na escola moveram-nos; no entanto, houve também movimentos outros. Além deste caminho, que se tornou o principal, houve desvios, igualmente inquietantes. Com estes corremos o risco de perder-nos, mas também arriscamos demorarmos mais, retomar o fôlego, desvencilhar-nos da ânsia pelo fim, ter outros (des)encontros (im)possíveis. Aqui destacamos um destes desvios, quando atentamos à diferença entre pesquisa sobre educação e em educação, sobre crianças e com crianças, à diferença entre a espionagem e a produção de conhecimento comum e heterogêneo na escola.

\section{A diferença entre a espionagem e a produção de conhecimento comum e heterogêneo em educação}

Atentamos à diferença entre a espionagem e a produção de conhecimento comum e heterogêneo na escola quando nos deparamos com o seguinte fragmento de conversa:

-Então, vocês viram que está gravando ali? Apontamos.

-Unhum... Responderam.

- Tá todo mundo aparecendo? Confirmamos.

-Siiim... asseguraram.

- Pronto! Tem também esse outro celular aqui, que vamos gravar a nossa voz... Pode ser?

Perguntamos.

-Unhum... consentiram.

-É espionagem! É espionagem... Enfatizava Robin Wood Gamer.

-É pra guardar essa conversa que a gente vai ter! Vai ser uma conversa bem legal! Pode ser? Confirmávamos.

-Tá, tá, tá... consentiram novamente.

-É espionagem! É espionagem... Continuava Robin Wood Gamer, demonstrando bom humor e desejo de participar da "espionagem"!

Robin Wood Gamer divertia-se com a espionagem, mas, por vezes, o tom da espionagem não é divertido. Por vezes, a pesquisa na escola é tomada enquanto espionagem no sentido conflitivo, injusto e depreciador, sem liberdade e autonomia, sem a garantia de assentimento ou consentimento das pessoas participantes das pesquisas, sem garantias de confidencialidade das informações, de privacidade e de proteção de identidades, conforme preceitua a já citada Resolução $\mathrm{n}^{\mathrm{o}} 510$.

Não raras vezes, quem pesquisa na escola é considerado como "mais uma pessoa para olhar a turma" - caracterização que ouvimos das crianças nos primeiros dias que acompanhávamos as 


\section{Dialogia}

ALBUQUERQUE, Fernanda Maria Santos; SALLES, Conceição Gislane Nóbrega Lima de; CARVALHO, Nádia Priscila de Lima. De espionagem à produção do conhecimento comum e heterogêneo na escola: a participação das crianças na pesquisa em educação

mesmas em suas experiências e que nos anunciou um desafio: a chegada de quem pesquisa até as salas de aula.

Obter o convite ou mesmo a permissão para realizar a pesquisa na sala de aula exige um atar de laço mais delicado, cumplicidade. Nesta pesquisa, por exemplo, manhãs se passavam sem que houvesse conversas com as professoras, cabendo apenas cumprimentos e trocas ligeiras de sorrisos. Para chegar às salas de aulas, foi preciso atentar às (im)possíveis e mais variadas maneiras de aproximarmo-nos das professoras.

Percebemos, por exemplo, que as professoras costumavam ficar na cozinha durante os intervalos das aulas, então, consideramos que a ida à cozinha para buscar água para beber poderia se dar durante os intervalos das aulas e, a partir de então, a capacidade de armazenamento da garrafa de água foi usada para atar laços - dispositivo que foi desdobrado em convites para tomar uma xícara de café (também com boa capacidade de armazenamento) e algumas conversas sobre tudo, inclusive sobre a pesquisa.

Nestes momentos, foi possível estar juntos, ou seja, partilhar a potência do encontro, da capacidade de desenvolver um projeto comum ou mesmo da potência do desencontro, do descobrimento das mútuas fragilidades (SKLIAR, 2019). A partir destes momentos, solicitamos e obtivemos as permissões das professoras para acessar as salas de aulas e, ainda com desafios dessa ordem, pudemos conversar um pouco mais sobre a pesquisa com as crianças.

Nas salas de aula, pudemos apresentarmo-nos como pesquisadoras, no entanto, havia ainda resquícios de espionagem. Ao fim das nossas apresentações, eram comuns acréscimos de informações pelas professoras no sentido de que, devido à nossa presença, as crianças deveriam ficar quietas, que supervisionaríamos as mesmas, conforme o relato abaixo:

\footnotetext{
Segui junto à professora Rosa Amarela. Ela recebeu a turma, fez uma oração e perguntou-me se eu gostaria de apresentar-me às crianças. Apresentei-me pela primeira vez às crianças em coletivo e, ao fim do primeiro momento da manhã com esta turma, ganhei dois desenhos lindos. Percebi que em outros momentos não tive a oportunidade de apresentar-me, apresentaram-me. Dessa forma, fiquei contente de poder falar por mim, muito embora, ao fim da minha fala, a professora tenha acrescentado que, devido à minha presença, as crianças deveriam ficar quietas, que eu escreveria no meu caderno sobre as crianças bagunceiras (esta última parte era bem possível mesmo, no entanto, sem o caráter denunciativo ou punitivo que parecia imbricado no acréscimo da professora) (DIÁRIO DE CAMPO, 2018).
}

Este relato trouxe consigo a reflexão de que a presença de quem realiza pesquisa na escola causa muita especulação, sobretudo, de denúncia. No entanto, o acompanhamento cúmplice das professoras, das crianças e de suas experiências, disparado através das mais variadas maneiras, 


\section{Dialogia}

ALBUQUERQUE, Fernanda Maria Santos; SALLES, Conceição Gislane Nóbrega Lima de; CARVALHO,

Nádia Priscila de Lima. De espionagem à produção do conhecimento comum e heterogêneo na escola: a participação das crianças na pesquisa em educação

possibilita-nos ir de uma espionagem alheia à pesquisa enquanto (con)vivência. Este movimento valida o processo de pesquisa, pois, evidencia o acesso à experiência, a consistência cartográfica e a produção de efeitos (PASSOS; KASTRUP; TEDESCO, 2016, p. 205-206).

Dessa forma, a resistência ao convívio transforma-se em convites para o mesmo, como o convite feito pelas crianças para um piquenique no recreio, quando escreveram-nos:

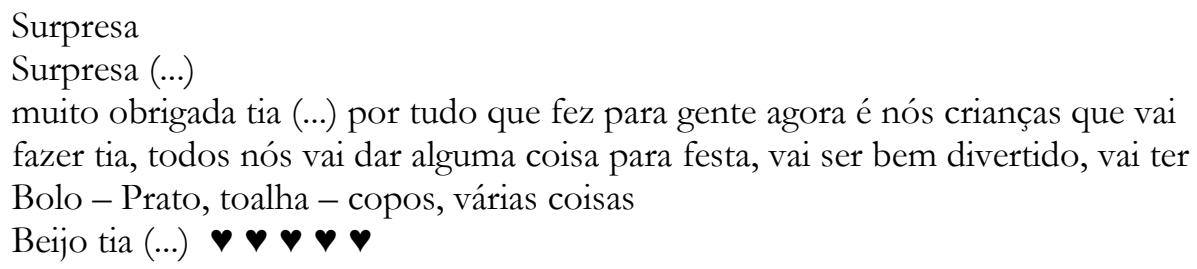

Além das crianças, as professoras Rosa Amarela e Jasmim também evidenciaram este movimento de transformação quando refletíamos acerca da pesquisa, em um dos últimos dias da pesquisa, ao final de uma conversa regada a agradecimentos recíprocos:

\footnotetext{
- Ave Maria, eu amei! Amei e aprendi muito! Muito mesmo! Expressou a professora Rosa Amarela.

-Eu não vi assim uma cobrança... uma fiscalização! Disse a professora Jasmim. -Eu me senti muito à vontade! Resumiu a professora Rosa Amarela. - A gente realizava, realmente, as coisas que a gente ia pra realizar! Eu explorei muito ela, botei ela pra trabalhar, pra me ajudar... mas foi muito gratificante! Eu, se eu resumisse, eu poderia dizer: aprendizagem. Eu acho que tanto você com a gente e eu com você. Resumiu a professora Jasmim.

- (...) Só tenho a agradecer! E minhas portas o próximo ano estão abertas... Concluiu a professora Rosa Amarela.
}

Ir de uma espionagem à produção de conhecimento comum e heterogêneo, de ensino e aprendizagem mútuos na escola diz-nos de movimentos e transformações de toda ordem na escola, de um fazer contínuo da educação. No entanto, diz-nos, sobretudo, de igualdade entre as pessoas, da educação enquanto direito humano e social, de onde emergem em conjunto pessoas, adultas ou crianças, livres e iguais para pensar e atuar em sua educação e no mundo.

\section{Considerações finais}

Educação é direito humano e social de pessoas adultas e crianças, indistintamente, e implica escolarização, cidadania escolar e equidade cidadã. Neste sentido, atentamos à participação das crianças na produção de conhecimento, à participação das crianças em seus currículos, processos de ensino e aprendizagem e experiências na escola. 
ALBUQUERQUE, Fernanda Maria Santos; SALLES, Conceição Gislane Nóbrega Lima de; CARVALHO, Nádia Priscila de Lima. De espionagem à produção do conhecimento comum e heterogêneo na escola: a participação das crianças na pesquisa em educação

Consideramos a infância como potência de pensamento imbricada à educação e destacamos a escuta das crianças na escola com atitude necessária à produção de conhecimento na área de educação, à própria educação. Analisamos e diferenciamos a presença da participação das crianças em pesquisas e, em específico, em pesquisas em educação. Dessa forma, atentamos à presença e à participação das mesmas em pesquisas de modo comum e heterogêneo, deslocando-nos de uma perspectiva adultocêntrica para pensar de outro modo a própria pesquisa, a educação e o direito à mesma.

A partir de uma pesquisa com inspiração cartográfica realizada com 41 (quarenta e uma) crianças e 06 (seis) professoras dos anos iniciais do Ensino Fundamental em torno dos (des)encontros (im)possíveis da infância, da experiência estética e da arte na escola, destacamos fragmentos que enfatizam o processo de realização de pesquisas nas escolas.

Crianças e pessoas adultas, discentes e professoras, seres diversos e flores levaram-nos a refletir acerca da diferença entre a espionagem alheia e a produção de conhecimento comum e heterogêneo em educação, do estar juntos, da (con)vivência, da validação do processo de pesquisa e da própria educação. Consideramos que a participação das crianças em pesquisas na escola aponta outros modos de pensar o acesso à educação e a luta por este direito.

\section{Referências}

ARENDT, Hannah. Entre o passado e o futuro. Trad. Mauro W. B. de Almeida. 5. ed. São Paulo: Perspectiva, 2000.

BRANDÃO, Z. Pesquisa em educação: conversas com pós-graduandos. Rio de Janeiro: Ed. PUCRio; São Paulo: Loyola, 2012.

BRANDÃO, Z. Direito à Educação e Cidadania Escolar. Boletim CEDES, Rio de Janeiro, v. 1, p. 1-7, 2014.

BRASIL. Resolução $n^{0}$ 510, de 07 de abril de 2016. Dispõe sobre as normas aplicáveis a pesquisas em Ciências Humanas e Sociais cujos procedimentos metodológicos envolvam a utilização de dados diretamente obtidos com os participantes ou de informações identificáveis ou que possam acarretar riscos maiores do que os existentes na vida cotidiana, na forma definida nesta Resolução. Seção 1, p. 44-46. Disponível em: < http://conselho.saude.gov.br/resolucoes/2016/reso510.pdf > Acesso em: 18 jun. 2018.

FERRAÇO, Carlos Eduardo; ALVES, Nilda. Conversas em redes e pesquisas com os cotidianos. In: RIBEIRO, Tiago; SOUZA, Rafael de; SAMPAIO, Carmen Sanches (org.). Conversas como metodologia de pesquisa: por que não? Rio de Janeiro: Ayvu, 2018.

KOHAN, Walter Omar. Infância, estrangeiridade e ignorância - Ensaios de filosofia e educação. Belo Horizonte: Autêntica, 2007. 
ALBUQUERQUE, Fernanda Maria Santos; SALLES, Conceição Gislane Nóbrega Lima de; CARVALHO,

Nádia Priscila de Lima. De espionagem à produção do conhecimento comum e heterogêneo na escola: a participação das crianças na pesquisa em educação

KRAMER, Sônia. Autoria e autorização: questões éticas na pesquisa com crianças. Cadernos de Pesquisa. Revista Quadrimestral. São Paulo, FCC, n. 116, p. 41-59, jul. 2002. Disponível em: <http://www.scielo.br/pdf/cp/n116/14398.pdf> Acesso em: 16 set. 2017.

ORGANIZAÇÃO DAS NAÇÕES UNIDAS (ONU). Declaração Universal dos Direitos do Homem. Adotada e aprovada em Assembleia Geral da ONU no dia 10 de dezembro de 1948. Disponível em: <https://nacoesunidas.org/wp-content/uploads/2018/10/DUDH.pdf> Acesso em: 20 mar. 2020.

PASSOS, Eduardo; KASTRUP, Virgínia; ESCÓSSIA, Liliana (org.). Pistas do método da cartografia: pesquisa-intervenção e produção de subjetividade. Porto Alegre: Sulina, 2015.

PASSOS, Eduardo; KASTRUP, Virgínia; TEDESCO, Silvia (org.). Pistas do método da cartografia: a experiência da pesquisa e o plano comum. Porto Alegre: Sulina, 2016.

PINTO, M.; SARMENTO, M. J. As crianças e a infância: definindo conceitos, delimitando o campo. In: PINTO, M.; SARMENTO, M. J. (org.). As crianças: contextos e identidades. Braga: Universidade do Minho, 1997.

ROLNIK, Suely. Cartografia Sentimental: transformações contemporâneas do desejo. 2. ed. Porto Alegre: Sulina; Editora da UFRGS, 2014.

SKLIAR, Carlos. A escuta das diferenças. Porto Alegre: Mediação, 2019.

Recebido em: 31 mar. 2020/ Aprovado em: 25 jun. 2020

\section{Cite como}

\section{(ABNT NBR 6023:2018)}

ALBUQUERQUE, Fernanda Maria Santos; SALLES, Conceição Gislane Nóbrega Lima de; CARVALHO, Nádia Priscila de Lima. De espionagem à produção do conhecimento comum e heterogêneo na escola: a participação das crianças na pesquisa em educação. Dialogia, São Paulo, n. 35, p. 52-63, maio/ago. 2020. Disponível em: https://doi.org/10.5585/dialogia.n35.16936.

\section{American Psychological Association (APA)}

Albuquerque, F. M. S., Salles, C. G. N. L., \& Carvalho, N. P. de L. (2020, maio/ago.). De espionagem à produção do conhecimento comum e heterogêneo na escola: a participação das crianças na pesquisa em educação. Dialogia, São Paulo, 35, p. 52-63.

https://doi.org/10.5585/dialogia.n35.16936. 